\title{
Wearable Technology for Enhanced Security
}

\author{
Agbaje M. Olugbenga, PhD \\ Babcock University \\ Department of Computer Science \\ Ogun State, Nigeria
}

\begin{abstract}
Wearable's comprise of sensors and have computational ability. Gadgets such as wristwatches, pens, and glasses with installed cameras are now available at cheap prices for user to purchase to monitor or securing themselves. Nigerian faced with several kidnapping in schools, homes and abduction for ransomed collection and other unlawful acts necessitate these reviews. The success of the wearable technology in medical uses prompted the research into application into security uses. The method of research is the use of case studies and literature search. This paper takes a look at the possible applications of the wearable technology to combat the cases of abduction and kidnapping in Nigeria.
\end{abstract}

\section{General Terms}

Security, sensors,technology.

\section{Keywords}

Computing, electronics,IoT, privacy, software,

ubiquitous, wearable.

\section{INTRODUCTION}

Wearables refer to technologies incorporated into items of clothing and accessories which can comfortably worn on the body. It performs same computing tasks as mobile phones and laptop computers. It provides sensory and scanning features not typically seen in mobile and laptop, such as biofeedback and tracking of physiological features. Wearable's comprises sensors and having computational power[1]. Wearable are clothing and accessories incorporating computer and advanced electronic technologies (PWC, 2014). Wearables are examples of the Internet of Things (IoT). They are part of the network of physical objects embedded with electronics, software, sensors and connectivity. This enable objects to exchange data with an operator and other connected devices, without needing human intervention [2] .

One of the earliest pieces of wearable technology was the calculator watch, introduced in the 1980s. The coming of portable computing in the early 1990s resulted in further experimentation in the technology with varying degrees of success [2].

[3] listed the state of today's world of wearable that our dayto-day apparel and accessories are turning into networked mobile devices attached to our body. The market is flooded with wearable including wristbands such as Fitbit and Jawbone. Attachable baby monitors such as Mimo and
Sproutling. Watches like the Apple Watch, and jewelry such as Cuff and Ringly.

Taking a look at the history of computer generations up to the present, we could divide it into three main types: mainframe computing, personal computing, and ubiquitous or pervasive computing[4]. The various divisions is based on the number of computers per users. The mainframe computing describes one large computer connected to many users and the second, personal computing, as one computer per person while the term ubiquitous computing however, was used in 1991 by Paul Weiser. Weiser depicted a world full of embedded sensing technologies to streamline and improve life [5].

Nigeria faced with several kidnapping in schools and homes are in dire need for solution. The purpose of such abduction is to collect ransom. This unlawful activities compel these reviews. [6] stated that some of the most interesting applications of wearable technology will come from three different technologies: Advanced wearable products, artificial intelligence and big data. These three technologies if well used in Nigeria in various aspect of our security can help curb the rate of kidnapping and abduction cases in Nigeria.

A disturbing case of kidnapped Chibok girls in Nigeria is yet to be unraveled two years. Theirs is a pathetic case in Africa.

Advances in telecommunication and networkingg lead to devices installation in cars and at home to enable tracking. Using car immobilizers and trackers are common in Nigeria. These could be bought at low prices. Devices such as wristwatches, pens, glasses with installed cameras are now available at cheap prices for user to monitor or secure them. The time is now to incorporate wearable technology into our society because of different high profile

cases that occurred in the last three to four years.

The success of the wearable technology in medical uses prompted the research into application into security uses. This paper takes a look at the possible applications of the wearable technology to combat the cases of abduction and kidnapping in Nigeria. The method of research is the use of case studies and literature search.

\section{LITERATURE REVIEW}

The term ubiquitous or pervasive computing was used in 1991 by Paul Weiser. Weiser depicted a world full of embedded sensing technologies to streamline and enhance life [5]. 
Table 1. Brief history of wearable devices Source (Hadi et al, 2014)

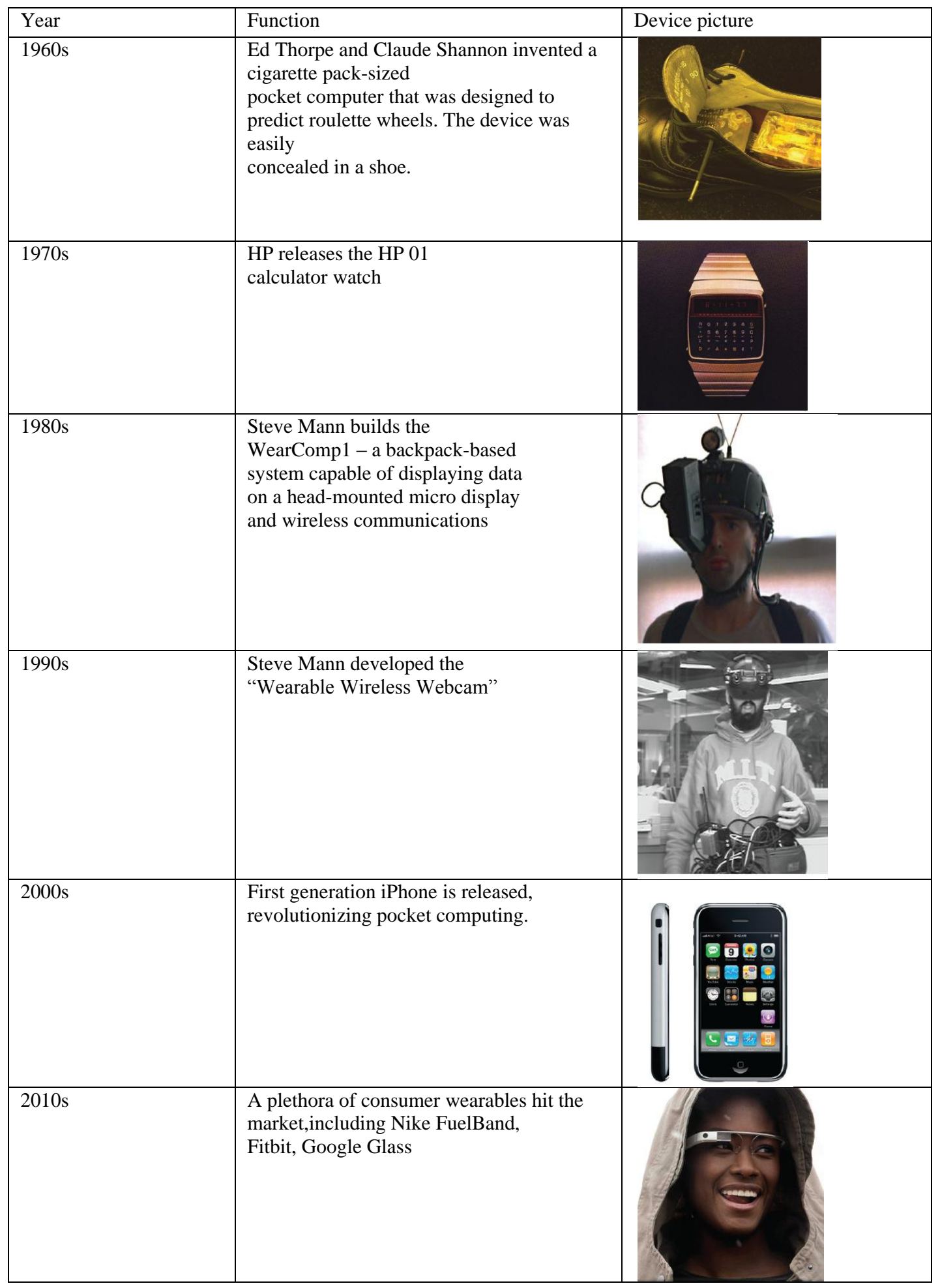

The Wearable Computers Group in MIT's Media Lab came after Weiser's vision [7]. Wearable computing extends Weiser's idea of incorporating computing into our everyday objects and activities. There is a difference between ubiquitous computing and wearable computing. A wearable computer is contact with and controlled by the user. The wearable's is always on and accessible[8] .
Ed Thorp and Claude Shannon introduced the first wearable computer in 1966, as a cigarette-pack sized analogue computer used to predict the outcome of roulette wheels. Using four buttons to show the speed of the wheel, the predicted results were transmitted by radio to an earpiece. A brief history of wearable is shown in the Table 1. 


\subsection{Why Wearable Technology?}

The use of wearable's technology is classified into personal and business. The use is found in fashion, fitness tracking, to synchronize data and communication from other gadgets. Also, specific health issue monitoring, gauge for alertness and energy levels, navigation tools, media devices and communication gadgets. With rising crime of abduction and kidnapping wearable technologies could track or alert the security personnel of the incident. Also, many abductors dispossess their prey means of communication from their abductees so no contact could be made. Therefore, wearable circuits worn in the body could track victims of abduction or kidnapping.

\subsection{Technologies in Wearable}

Wearable technology will come from three different technologies stated below:

- Advanced wearable products: The three main wearable products are body sensors, smart glasses and smart watches.

- Artificial intelligence platforms: Technologies like Now (Google), Siri (Apple), Cortana (Microsoft) and, most recent, IBM's decision to provide mobile app developers with access to its supercomputer platform.

- Big data: Provides information individual location, search history data or advertisement preferences [6].

\subsection{Advantages of Wearables}

Wearables can provide consumer benefits in the areas of health care and wellness. It can store data locally, broadcast

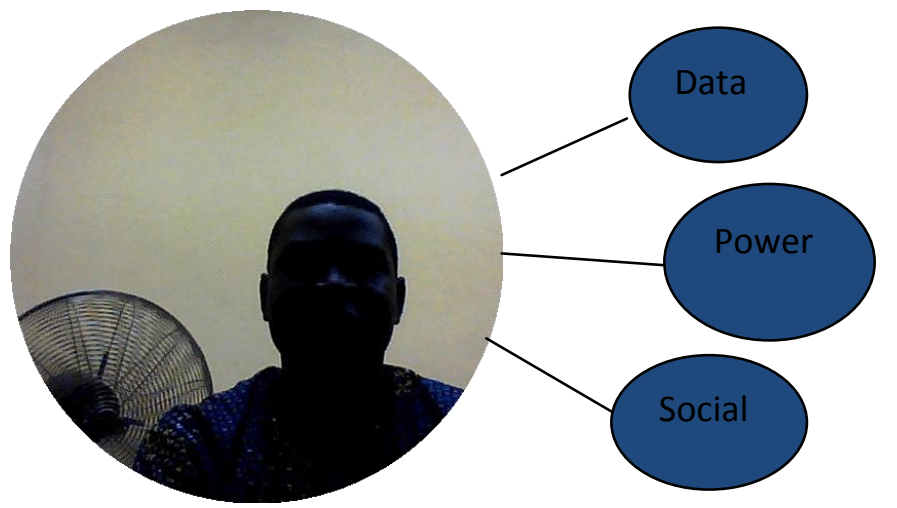

and stored on a cloud. These can provide increased convenience and improved health services.

\subsection{Disadvantages of Wearables}

It raises privacy and security concerns. They challenge traditional privacy principles and pose a distinct challenge to the collection, use, and storage of health, location, financial, and other sensitive information.

\subsection{Applications of Wearables}

Wearables for health [1]. Health and fitness, and other medical applications, are areas where wearable's are expected to play a transformative role. However, the application of wearable has potential in any industry where hands-free data collection is valued. Wearable's can be divided based on consumer or non-consumer applications. These two categories is subdivided based on product targets: General consumer, Fitness and sports, Fashion and apparel, Home automation and remote identification, Gaming and recreation, Defense and security, Enterprise and industrial, Healthcare.

\subsection{Architecture of Wearables Technology}

This architecture shows three parts of wearable technology:

Data: Data is a binary format and needs storage prior to transfering the data from one place to another.

Power: It has three main parts i,e how power is generated, transferred from one place to another and stored.

Social: wearable's are used at so many different places and plays a role in our culture, social connections and relationships [9].

\author{
Transfer \\ Storage \\ creation \\ Generation \\ Sending \\ Memory \\ Interaction \\ "real Life"
}

Fig.1 : Simple architecture of wearable devices[10].

\section{PROPOSED ARCHITECTURE FOR ANTI-KIDNAPPING AND ABDUCTION USING WEARABLE DEVICE.}

In this paper wearables are clothing and accessories incorporating computer and advanced electronic technologies. 


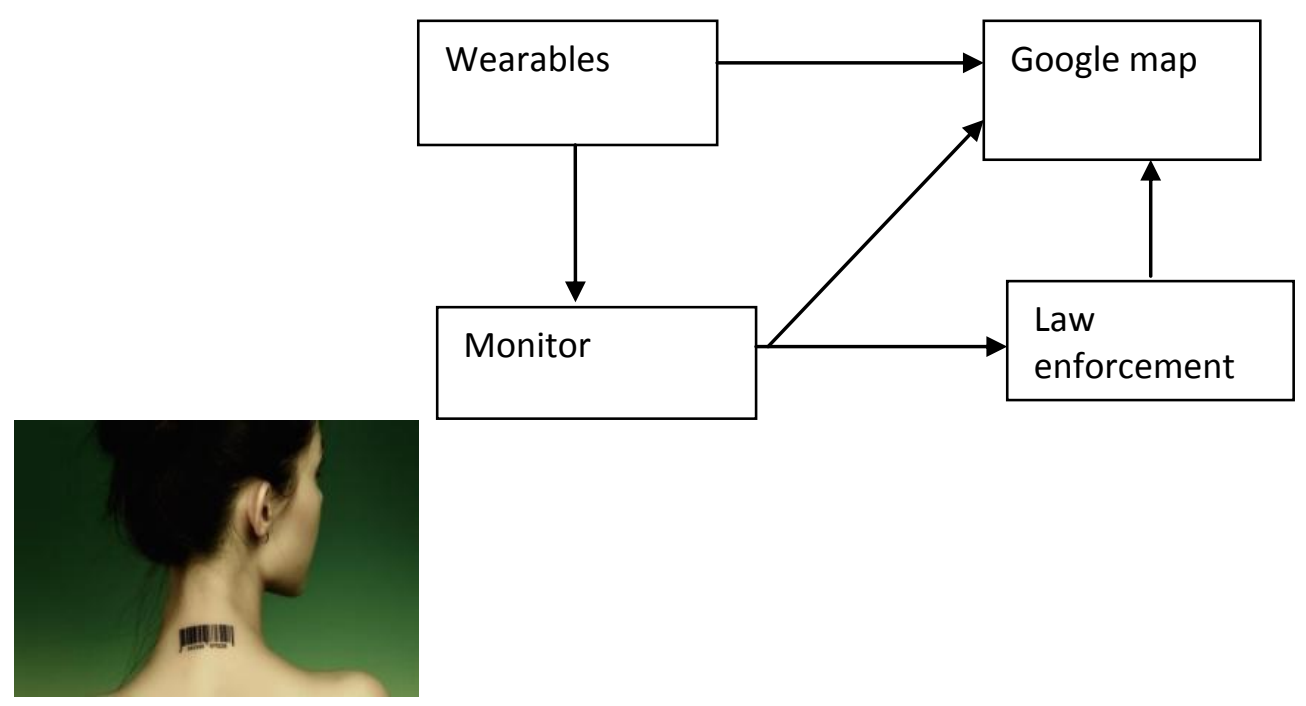

Fig. 2: Proposed architecture.

Throughout our research, we used the following description to define wearable technology. The proposed architecture in figure 2 comprises of four major block. The wearable may be of any form with blue tooth or wifi capability that could be detected using a form of monitor i.e a cell phone or ipad connected to google map for location and positioning and also connected tp the law enforcement agency in chage of cybercrime for monitoring in case of any breach of the law.

The wearables used for health are connected self - monitored devices with smart sensors, and make use of a web connection, using Bluetooth to connect to your smartphone. They use these sensors to connect to you as a person, and they help you to achieve goals such as staying fit, active, losing weight or being more organised. This devices have the capacity to serve as a security device and could fit into this architcture.

Smart jewellery is aimed at women, and the most common usage is to notify the user of texts, calls or emails when their phone is out of reach. Smart watches are wrist-worn devices that connect to your mobile phone to act as mini-windows onto your digital life. Telling time is an after-thought for smart watches; they inform you about calls, messages and email notifications on social media.

The implantables are a group of wearable you have to carry with you wherever you go. These are devices attached somewhere under your skin by surgery.

\section{DISCUSSION}

The paper made a research into the various wearables present in the online store in Nigeria price range to know the avalability. The table below shows some of the wearable products on some popular online stores.

Despite the religious and social beliefs of people there is a gradual increase in awareness of wearables in Nigeria. Table 2 shows some of the products available. The range of prices of the various products also ranges $\$ 14$ to $\$ 200$.

Table 2. Online wearables and sites

\begin{tabular}{|l|c|c|c|}
\hline ONLINE STORE & JUMIA.COM & KONGA.COM & DEALDEY.COM \\
\hline PRODUCTS & & & \\
\hline $\begin{array}{l}\text { I5 Plus blue tooth } \\
\text { intelligent traker(walkout } \\
\text { monitor) }\end{array}$ & $\checkmark$ & $\checkmark$ & $\checkmark$ \\
\hline $\begin{array}{l}\text { Pedometer heart rate } \\
\text { monitor with fat analyzer }\end{array}$ & $\checkmark$ & $\checkmark$ & $\checkmark$ \\
\hline $\begin{array}{l}\text { Tile tracker bluetooth } \\
\text { tracker-find lost item }\end{array}$ & $\checkmark$ & $\checkmark$ & $\checkmark$ \\
\hline $\begin{array}{l}\text { Generic Car GPS Tracker } \\
\text { with SOS Emergency } \\
\text { Phone Call Black }\end{array}$ & $\checkmark$ & & $\checkmark$ \\
\hline $\begin{array}{l}\text { Generic 4.0 Tracer GPS } \\
\text { Locator Wallet Key Pet } \\
\text { Finder }\end{array}$ & $\checkmark$ & $\checkmark$ & $\checkmark$ \\
\hline $\begin{array}{l}\text { Rohs Digital Personal } \\
\text { Safety Alarm Device }\end{array}$ & $\checkmark$ & $\checkmark$ & \\
\hline
\end{tabular}




\begin{tabular}{|l|c|c|c|}
\hline $\begin{array}{l}\text { Spy keyholder,watch, } \\
\text { table clock cap,pen. } \\
\text { USB,sunshade glasses }\end{array}$ & $\checkmark$ & $\checkmark$ & $\checkmark$ \\
\hline Blood presure monitor & $\checkmark$ & $\checkmark$ & $\checkmark$ \\
\hline
\end{tabular}

\subsection{Future of Wearable}

There is increased speed for the various chips embedded in wearables from the current survey.

They also have longer battery lifespan, smaller, faster and more sensitive. Innovations are multiplying the rate at which breakthroughs can happen in wearable. Their has been a progression of these same devices from desks and pockets to being displayed on our bodies. It opens the door for new forms of computing that impact the way we live, work and socialize [11].

Innovations in wearable technology will develop first through wristbands. Other jewelry-like devices will follow - including rings and necklaces. There is much speculation on use of computerized glasses. Analysis suggests that while these displays may offer a unique range of options, their development to the full range of services that like smart clothing might offer is limited. Sensors embedded within clothing will provide a with array of benefits over the next two to five years, with several focused on improving our health and well-being.

Accepting technology that will embed wearable's in our bodies will take-off in the future. From 2018, bio-integrated computing will advance from where it is today, to a place where early adopters will experiment. For those not ready for the scalpel, wearables will still change the way we work, live and play [11].

Wearable technology is on the rise in both personal and business use. One out of five American adults have a wearable device according to the 2014 Price Waterhouse Coopers Wearable Future Report[12]

Smartwatches are a second high-profile sector and while wearable devices have been around for years, it has only gained mass-market attention with introducing new models by Samsung and later by Apple. The now defunct Google Glass gained media attention, but the project ground to a halt in early 2015, with Google stopping device sales. In healthcare, wearables have being in use, for example in detecting health disorders such as sleep apnea. A study in 2014 by MSI and McAfee reported that $70 \%$ of people think that wearable technologies will soon send health vitals readings to physicians[13] .

Medical professionals Google Glass Surgeon organized themselves into Wearable Technology in Healthcare Society (WATCH) . They aim for collaboration and valid use of wearable in healthcare. In sports, wearable has applications in monitoring and real time feedback for athletes[14][15].

Examples of wearables are shown in the figure 3-6:

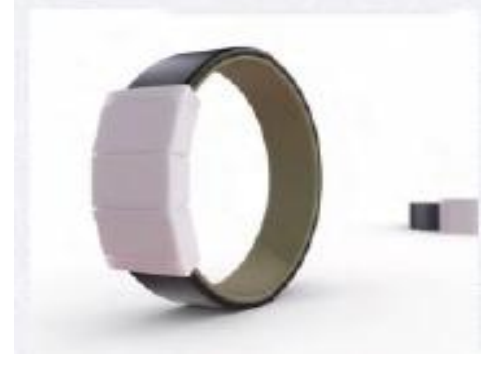

Fig. 3:Smartwatch respond to save long distance relationships[11]

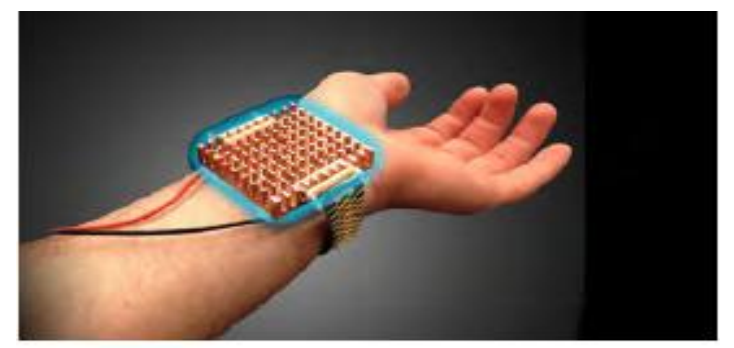

Fig. 4:Responsive bracelets send thermoelectric pulses to heat or cool persons entire body[11].

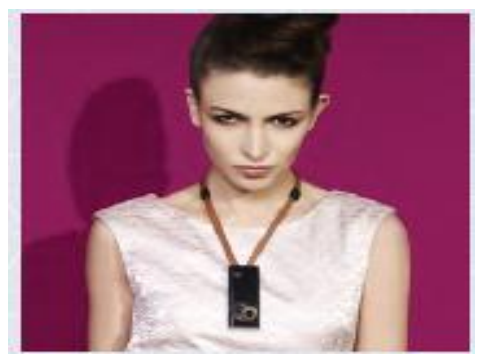

Fig. 5: Wearable Life blogs camera by snapping camera throughout the day [11].

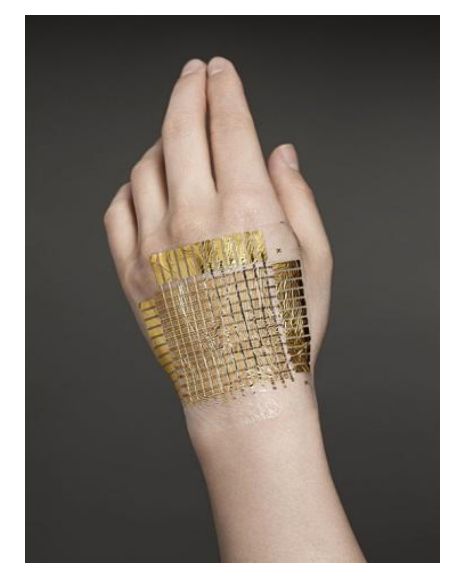

Fig. 6: Flexible electronics circuit develop at University of Tokyo [16]

Figure 6 shows one of the most flexible, thinnest and bendable circuits. These circuits are cheap to make. It remains functional when crumbled like paper. The sheets are one fifth 
of the thickness of common kitchen rap and 30 times lighter than paper.

\section{CONCLUSION}

From the various literature and case studies this research shows there is a wearable future around the corner.

This paper looked at the various technologies in place and that are workable, based on where wearable technology is today and where we believe it is heading.

Depending on your perspective, some of use cases might seem distasteful, or motivational. Regardless, experience shows that if something is possible then it is likely to enter the marketplace as a commercial product or service.

Wearable technology still raises some serious privacy and related questions we think you should know, if you are not already.

\section{ACKNOWLEDGMENTS}

Thanks to Funke for reading this paper.

\section{REFERENCES}

[1] Hadi, S., Emily M., \& Nirusan, R. (2014).Wearable Tech: Leveraging Canadian Innovation to Improve Health, Pg 1-45.

[2] Lexinnova (2016).Wearable technology: patent landscape analysis, pg1-18.

[3] Janice, P., \& Lin, G.(2015), Privacy, Security, and Wearable Technology, ABA Section of Intellectual Property Law, Published in Landslide, Volume 8, Number 2, (02015 by the American Bar Association.pg18.

[4] Abowd, G. D. (2012). What next, ubicomp? : celebrating an intellectual disappearing act. Paper presented at the Proceedings of the 2012 ACM Conference on Ubiquitous Computing.
[5] Weiser, M. (1991). The computer for the 21st century. Scientific American, 265(3),94-104

[6] Andrew, S. (2014).Mind-blowing Uses of Wearable Technology.

[7] Krumm, J. (2009). Ubiquitous Computing Fundamentals, Taylor \& Francis.

[8] Mann, S. (1999). Definition of a Wearable Computer. From http://wearcomp.org/wearcompdef.html

[9] Maidment, D. (2014). Advanced Architectures and Technologies for the Development of Wearable Devices

[10] Mehdi \& Alharby(2016):.Purpose, Scope, and Technical Considerations of Wearable Technologies, Information Resources Management (IRM) proceedings,DOI: 10.4018/978-1-5225-0069-8.ch001

[11] PSFK (2016) .The Future of Wearable Tech: Key Trends Driving The Form And Function Of Personal Devices, www.psfk.com/future-of-wearable-tech /iq.intel.com/future-of-wearable-tech downloaded(13-416)

[12] Zalud, B. (2015). "The Age of Wearables Is on Us". SDM: 72-73.

[13] Eichorn, K. \& Ross, E. ( 2014). "U.S. Consumers Predict Unprecedented Connectivity in 2025, but Security and Privacy Concerns Linger" - via ProQuest

[14] Duncan, S.(2009).The Rise of the Virtual Trainer . Product Design and Development

[15] Simon, J.(2013) In pro sports, wearabletech is already mainstream. Wearable Tech Watch.

[16] Martin K. Et al (2013). An ultra - lightweight design for imperceptible plastic electronics. Nature. doi 10.1038/nature 12314 